\title{
Nonlinear Finite Element Analysis of the Limit State and Pressure of Dented X60 Steel Pipeline
}

\author{
Xiaoben LIU*, Hong ZHANG**, Baodong WANG***, Mengying XIA****, \\ Kai TANG******, Kai WU******* \\ *China University of Petroleum (Beijing), Beijing 102249, China, E-mail: liuxiaoben1991@126.com \\ **China University of Petroleum (Beijing), Beijing 102249, China, E-mail: hzhang@cup.edu.cn \\ ***China University of Petroleum (Beijing), Beijing 102249, China, E-mail: wbd3522@163.com \\ ****China University of Petroleum (Beijing), Beijing 102249, China, E-mail: xiamengying@163.com \\ *****Beijing Aviaion Oil Construction Company, Beijing 100621, China, E-mail: tk1987@189.com \\ ******China University of Petroleum (Beijing), Beijing 102249, China, E-mail: wk0609@126.com \\ cross $^{\text {ref }}$ http://dx.doi.org/10.5755/j01.mech.23.6.17338
}

\section{Introduction}

Pipelines are the most common structures for long distance transportation of oil and gas [1], which are also called lifelines for their importance [2]. But as typical shell structures, they are vulnerable to external loads, especially for those with defects. Dent is one of the main kind of defects for pipelines. Dawson S J [3] reported that, there are 9851 dents existed in the $7022 \mathrm{~km}$ long pipelines in Europe. A lot of literatures are available for assessment of dented pipes. Ellinas [4] proposed a relationship for dent depth with external load. Wu [5] analyzed the damage degree of oil gas pipes with type II plain. Yang [6] studied the dent shape calculation methods by interpolation model. Jiao [7] concluded the general integrity assessment procedure for dented pipes. M. Allouti [8] found that, for shallow dent, influence of dent depth on critical pressure of A37 steel pipe is negligible. Limam [9] investigated the collapse behaviour of dented tubes under combined bending and internal pressure. Zhang [10] conducted a numerical analysis for pipe's dent behaviour impacted by perilous rock. Although numbers of researches have been done, so far, no accurate limit pressure prediction model for dented X60 pipe has been propose for engineering applicability.

To fill this gap, efforts were put in this study to investigate the failure process of dented X60 steel pipe under internal pressure with a validated rigorous 3D nonlinear finite element method. Effects of common influence factors, e.g., the pipe initial pressure, ratio of diameter to wall thickness, dent depth and diameter of indenter, on failure pressure were discussed in detail. Based on the parametric analysis results and regression method, an engineering applicable limit pressure prediction model was presented. This proposed method can be referenced for the integrity assessment of X60 pipeline.

\section{Numerical modelling}

General finite element code package ABAQUS [11] was used in this study to establish a finite element model for limit pressure analysis of dented pipe. Due to the symmetry of the model, only one fourth of the total model was needed in the numerical model, as shown in Fig. 1. The indenter was built by $3 \mathrm{D}$ analytical rigid surface to reduce the calculation time, with its bottom assumed to be a sphere, for only pipe performance is concerned in this study. To apply the constrain conditions on the indenter, a reference point was defined at the center of the top surface of indenter. Eight node hexahedral solid elements with reduced integration (C3D8R) were used to simulate the pipe. Fine mesh for pipe was used in the contact area between the pipe and indenter, while coarse mesh was used for other parts both axially and circumferentially. In order to capture the accurate deformation in the pipe section, the pipe wall was discretized to three equal sized solid elements. Surface to surface contact approach implemented in ABAQUS was used to model the interaction between the indenter and pipe. Suitable boundaries were applied to conduct a reasonable numerical analysis. As shown in Fig. 1, surface A and B were applied with symmetrical boundary conditions, Surface C's motion was restrained in $\mathrm{XY}$ plane, and the bottom line of the pipe was constrained to eliminate the rigid motion during the analysis. Pipe length in the model was set to be four times of pipe diameter.

The pipe was subjected to four load steps during the analysis. An internal pressure was proposed fist in the inside of the pipe to simulate the service condition. Next, the indenter was displaced by imposing a vertical downward displacement to simulate the denting process. After this, the indenter was displaced again with a vertical outward displacement to release the dent. Finally, internal pressure was applied to the inner surface of pipe to investigate the pipe performance and determine the limit pressure. It should to be noticed that the model was parameterized by programing with PY code [11], which makes a series of numerical study easier to accomplish.

\section{Failure criteria and experimental validation}

Net section failure criteria was adopted in this study as it is commonly used in limit pressure analysis for defected pipe structures [7, 12]. According to this criteria, the pipe's failure was considered to occur once the minimum Von Mises stress in the critical pipe wall section reaches to the flow stress $\sigma_{f}$. The commonly used flow stress value can be assumed as:

$$
\left.\begin{array}{l}
\sigma_{f}=\left(\sigma_{s}+\sigma_{b}\right) / 2, \\
\sigma_{f}=\sigma_{b},
\end{array}\right\}
$$


where $\sigma_{s}$ is the yield strength of pipe steel, $\sigma_{b}$ is the ultimate strength of pipe steel.

Full scale experimental results [13] were used here to determine the correct value of flow stress for limit pressure analysis of dented pipe. An API X52 steel pipe was adopted to conducted the experiment, the pipe diameter $D$ and pipe wall thickness $t$ are $323.8 \mathrm{~mm}$ and $4.775 \mathrm{~mm}$, respectively. The yield strength $\sigma_{s}$ and ultimate strength $\sigma_{b}$ of the steel are $437 \mathrm{MPa}$ and 567.2MPa, respectively. The dent depth $h$ was $0.12 D$. Burst pressure of this pipe was 16.05MPa. Parameters were all employed to conduct a comparison numerical investigation with the experiment.

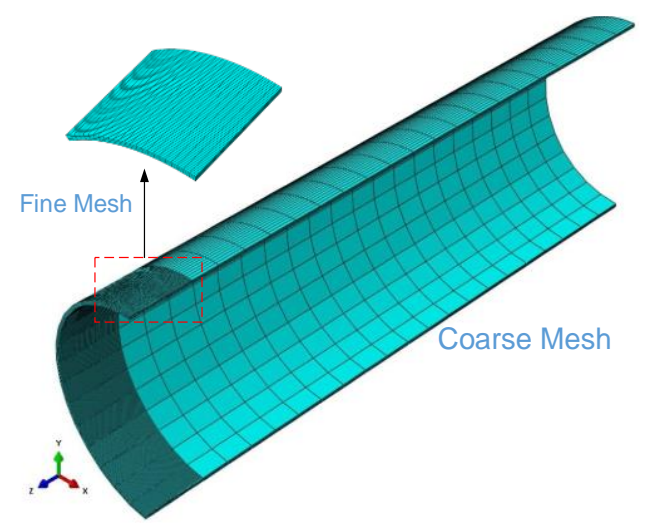

$\mathrm{a}$

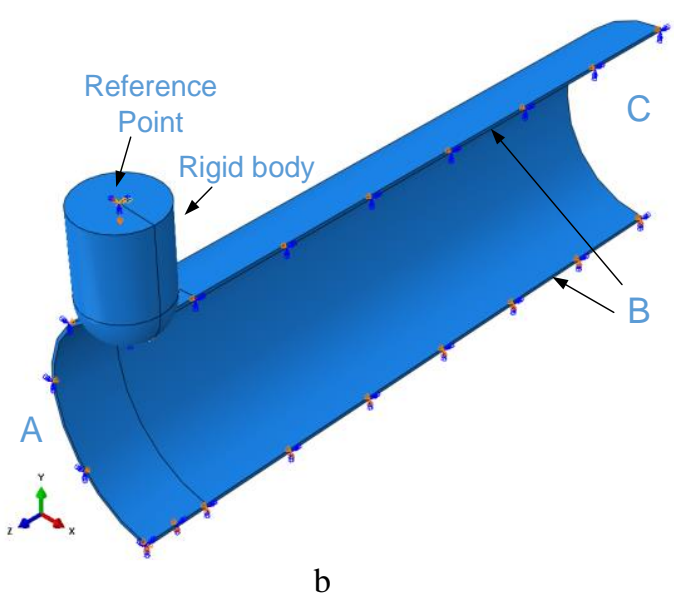

Fig. $13 \mathrm{D}$ nonlinear finite element model: a-mesh pipe, bboundaries of the model

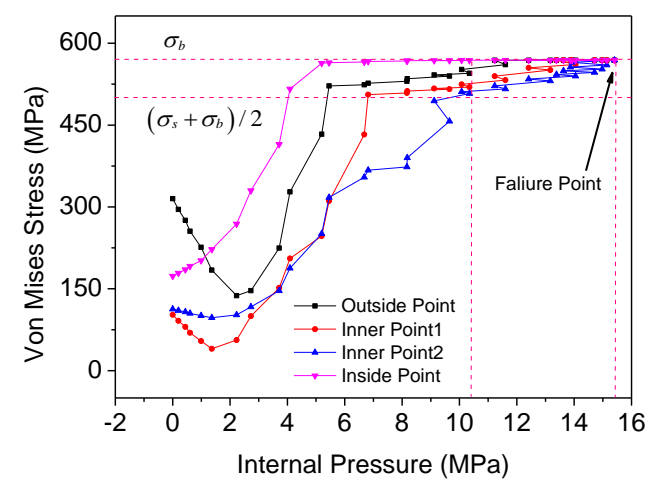

Fig. 2 Von Mises Stress trends in the critical wall section in pressure loading step

Fig. 2 shows the von Mises stress trends of the critical wall section under internal pressure load. It can be derived that stresses in the superficial points of pipe wall are larger than those of inner points. This is mainly caused by the bending strain in the dent area. And limit pressures determined by $\sigma_{b}$ and $\left(\sigma_{b}+\sigma_{b}\right) / 2$ are $15.4 \mathrm{MPa}$ and 10.5 MPa. It is obvious that, taking $\sigma_{b}$ as the flow stress is more reasonable for failure predicting of dented pipe.

Inner Point1

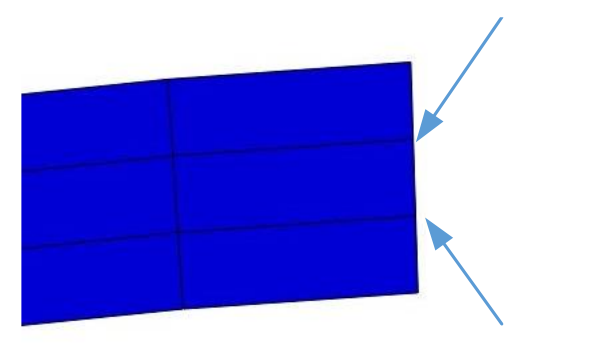

Fig. 3 Sketch of the inter point positions

\section{Failure analysis of dented X60 pipe}

\subsection{X60 steel property model}

API X60 pipe steel used in the Shanxi-Beijing Natural Gas Pipeline was considered in the numerical study. Stress strain relationship of X60 steel is illustrated in Fig. 4. Nominal stress-strain curve was obtained by tensile tests and then transformed to true stress-strain curve by the following formula:

$$
\left.\begin{array}{l}
\varepsilon_{\text {ture }}=\ln 1+\varepsilon_{\text {nom }}, \\
\sigma_{\text {ture }}=\sigma_{\text {nom }} 1+\varepsilon_{\text {nom }},
\end{array}\right\}
$$

where $\sigma_{\text {nom }}, \varepsilon_{\text {nom }}$ are nominal stress and strain, respectively; $\sigma_{\text {true }}, \varepsilon_{\text {true }}$ are true stress and strain, respectively.

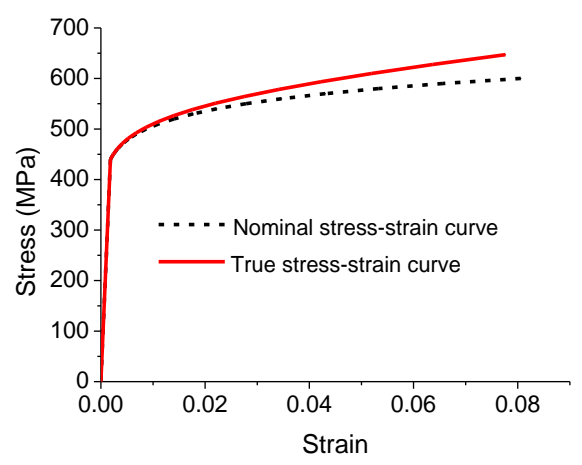

Fig. 4 Stress-strain curve for X60 steel

\subsection{Critical dent depth}

The main purpose of this study is to investigate the limit pressure of dented pipe. But it should be mentioned that, the failure may occur to the pipe in the denting process, if the external load is extremely large. So the critical dent depth of X60 pipe was discussed first. The diameter and wall thickness are $660 \mathrm{~mm}$ and $8.7 \mathrm{~mm}$, and the diameter of the indenter was set to be $50 \mathrm{~mm}$. Fig. 5 illustrates the Mises stress trends of the four points in the critical wall section in pipe. The superficial points get larger stress during the whole load process, and when the stress 
of the inner point reaches $\sigma_{f}$. the pipe can be considered as failure. The critical dent depth for this case is $0.168 D$. Thus, in limit pressure analysis of dented pipe, the dent depth must be less than the critical dent depth.

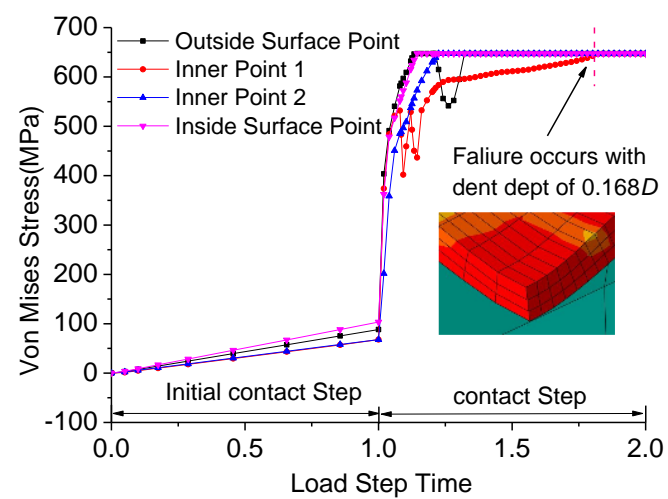

Fig. 5 Von Mises Stress trends in the critical wall section in contact step

\subsection{Burst failure process of dented X60 pipe}

In this section, a full burst failure process of a dented X60 steel pipe was performed. The pipe geometrical parameters were the same as above. While the diameter of indenter was changed to $80 \mathrm{~mm}$ to maintain a larger dent depth. Fig. 6 shows the Mises stress trends in critical wall section during the load process. In the dent load step the entire section becomes highly plastic which is similar to Fig. 5, but the inner point didn't reach $\sigma_{f}$, and when indenter release the dent load, residual stresses retain in the section. Finally the failure to the section when the stress of the inner point reaches $\sigma_{f}$ under pressure load.

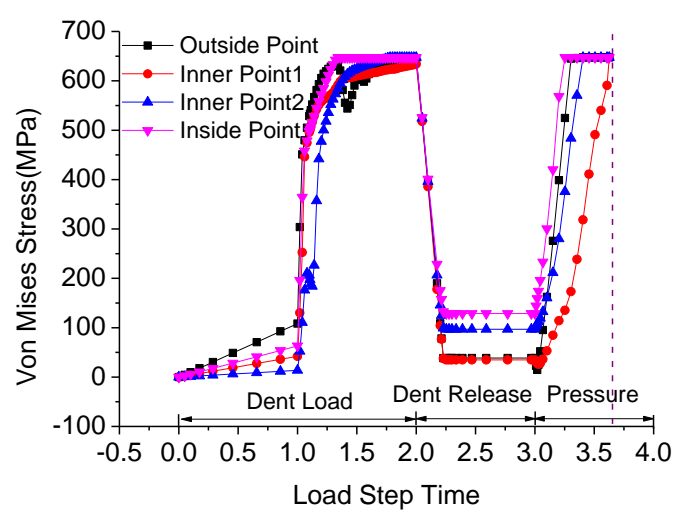

Fig. 6 Von Mises Stress trends in the critical wall section in burst process

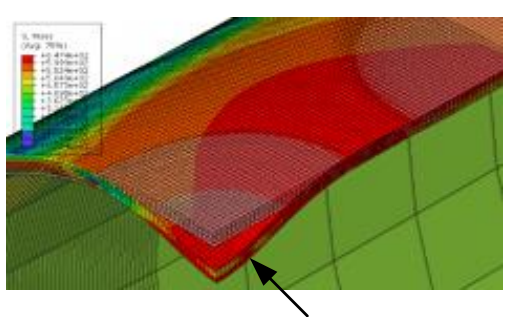

Failure Section

Fig. 7 Failure section under burst pressure
Fig. 7 illustrates the failure section under internal pressure. It can be derived that; failure occurs in the boundary of the dent area along the pipe axial direction. The influence factors on limit pressure for dented X60 steel pipe will be investigated in detail in the following part by this method.

\section{Results and Discussion}

\subsection{Effects of dent depth}

Dent depth reflects the damage degree of the pipe caused by the indenter [5]. In this section, influences of dent depth on pipe failure was studied. The diameter of the indenter was also set to be $120 \mathrm{~mm}$, and five values of dent depth $h$ was considered as $0.04 D, 0.08 D, 0.12 D, 0.16 D$, $0.2 D$. Fig. 8 illustrates the relationship of the limit pressure plim with dent depth. It can be obtained that, if $h<0.08 \mathrm{D}$, $p_{\text {lim }}$ almost remain the same value $16.9 \mathrm{MPa}$, which is very close to the burst pressure of the perfect pipe $17.05 \mathrm{MPa}$ calculated by $\sigma_{u} / 2 \mathrm{D}$. This is consistent with previous results for another kind of steel pipeline [8]. The result also reflects that critical dent depth of $6 \%$ for pressurized pipe suggested by ASME $[14,15]$ is conservative from the view of pipe strength. If $h>0.12 D, p_{\text {lim }}$ decreases as $h$ increases. The limit stress state of dent area when pipe failure occurs is also investigated here. If dent depth $h$ is $0.04 D$, the pipe expands obviously with regard to the original pipe position and failure occurs in the center point of dent area. While, if dent depth $h$ is $0.16 D$, the pipe has no obvious deformation with regard to the original pipe position and failure occurs in the side of the dent area along the axial direction.

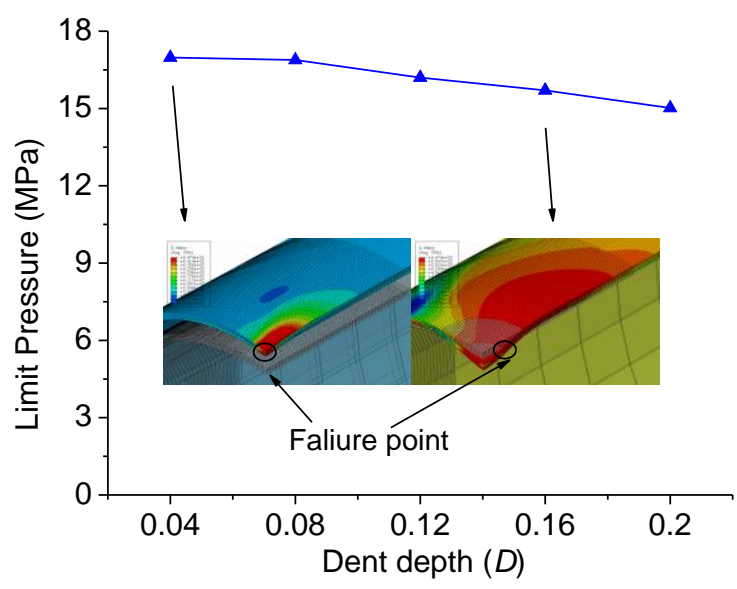

Fig. 8 Effects of dent depth on limit pressure

For all the stress is so large, which is not suitable for comparison analysis, the plastic strain $P E$ of the inner point (failure point) in the pipe was investigated here. Fig. 9 shows the distribution of $P E$ in dent area along the axial direction.

It can be obtained that, with the increase of dent depth, $P E$ increases, which is consistent with the large strain induced by the indenter. What's more, when dent depth $h$ is less than $0.08 D, P E$ peaks in the center of dent area, so pipe failure occurs in the center, while when $h$ is larger than $0.12 D, P E$ peaks in the boundary of dent area, so pipe failure occurs in the side. 


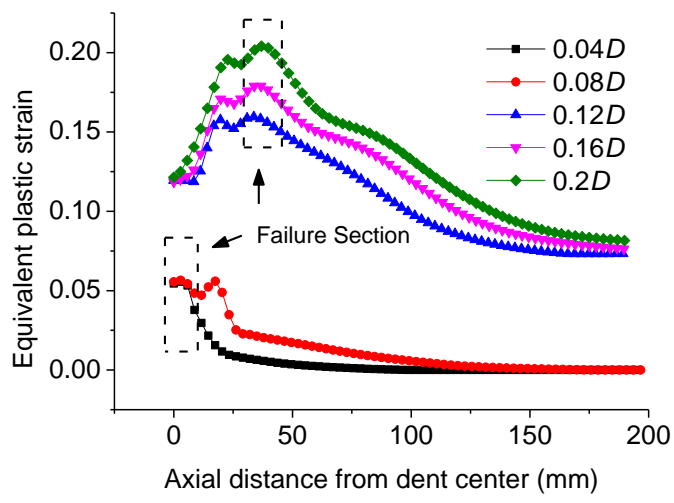

Fig. 9 Equivalent plastic strain distribution of inner point along axial direction

\subsection{Effects of indenter diameter}

The indenter diameter $D_{\text {ind }}$ directly influences the curvature of the dent area which finally affects the stress and strain in this area. In this section five diameter values were considered, i.e., 50, 80, 120, 160 and $200 \mathrm{~mm}$. Fig. 10 illustrates the relationship of the limit pressure $p_{\text {lim }}$ with indenter diameter under different dent depth conditions.

The limit pressure $p_{\text {lim }}$ increases with the increase of indenter diameter $D_{\text {Ind }}$, for larger bending strain will be induced by a smaller indenter. It indicates that, the dented pipe with same dent depth is more dangerous if the dent area is smaller. And the pipeline operators must pay more attention to the sharp dents with large depth and very small areas.

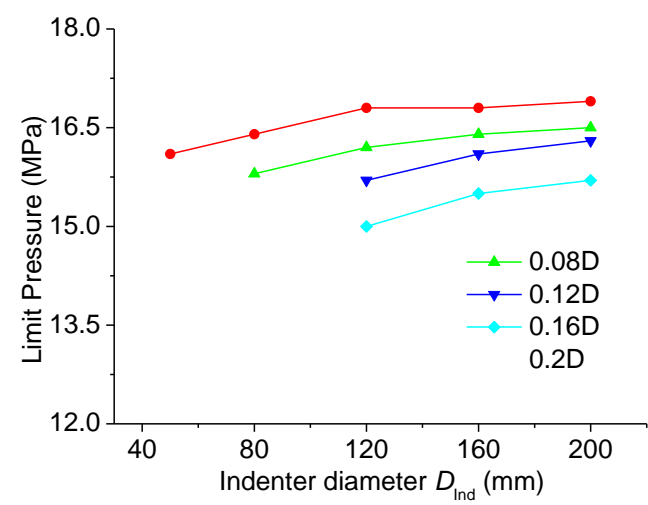

Fig. 10 Effects of indenter diameter on pipe limit pressure

\subsection{Effects of initial internal pressure}

The initial internal pressure will change the initial stress state of the pipe. Four internal pressures were taken into consideration, i.e., 3, 5, 6, 4, $8 \mathrm{MPa}$. Fig. 11 shows the relationship between the limit pressure $p_{\text {lim }}$ and internal pressure with different dent depths. Results show that, if dent depth $h<0.04, p_{\text {lim }}$ almost remain the same value with the increase of internal pressure $p$, while if dent depth $h>0.08$, the limit pressure $p_{\text {lim }}$ decreases with the increase of internal pressure $p$.

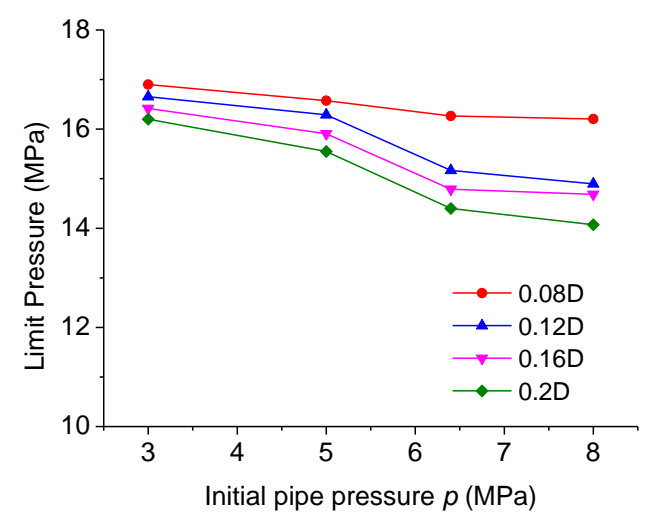

Fig. 11 Effects of pipe initial pressure on pipe limit pressure

\subsection{Effects of ratio of diameter to wall thickness}

Ratio of diameter to wall thickness $D / t$ affects the pipe stiffness and stress state in working conditions. In this section, four wall thicknesses were considered, i.e., 7.14, 8, 8.7 and $10.3 \mathrm{~mm}$. The corresponding values of $D / t$ are 92.4, 82.5, 75.8 and 64. Relationship between limit pressure $p_{\text {lim }}$ and $D / t$ is shown in Fig. 12. It is easy to obtain that, with the increase of $D / t, p_{\text {lim }}$ decreases, for thinner wall thickness leads to a larger hoop stress which makes failure occur easier.

\section{Prediction of the limit pressure}

Based on a series of FE analyses, the functional relationship for limit pressure of dented X60 steel pipe and the main influence factors can be derived. For 3D nonlinear finite element model is quite time consuming and needs some professionals to calculate, a simple limit pressure prediction model was proposed. Power functions are assumed to describe relationships. And the equation is as follows:

$$
\begin{aligned}
p_{\text {lim }}= & a_{1} \times(D / t)^{a_{2}} \times\left[-(h / D)^{a_{3}}+a_{4}\right] \times \\
& \left(D_{\text {Ind }} / D\right)^{a_{5}}\left(p / \sigma_{u}\right)^{a_{6}}+a_{7},
\end{aligned}
$$

where $a_{1} \sim a_{7}$ are regression coefficients.

Based on the numerical results for limit pressure, all the coefficients can be calculated by the nonlinear fit tool provided by program package MATLAB, then the prediction equation can be derived Eq. (4).

$$
\begin{aligned}
& p_{\text {lim }}=2.93\left(\frac{D}{t}\right)^{0.73}\left[-\left(\frac{h}{D}\right)^{0.021}+0.61\right] \\
& \left(\frac{D_{\text {Ind }}}{D}\right)^{-0.0255}\left(\frac{p}{\sigma_{u}}\right)^{0.0169}+38.97
\end{aligned}
$$

where $64<D / t<92, h>0.08 D, 50 \mathrm{~mm}<D_{\text {Ind }}<120 \mathrm{~mm}$, $p<8 \mathrm{MPa}, \sigma_{u}=647 \mathrm{MPa}$

Fig. 13 shows that the predicted results by Eq. (4) are in good agreement with the numerical simulation results. 


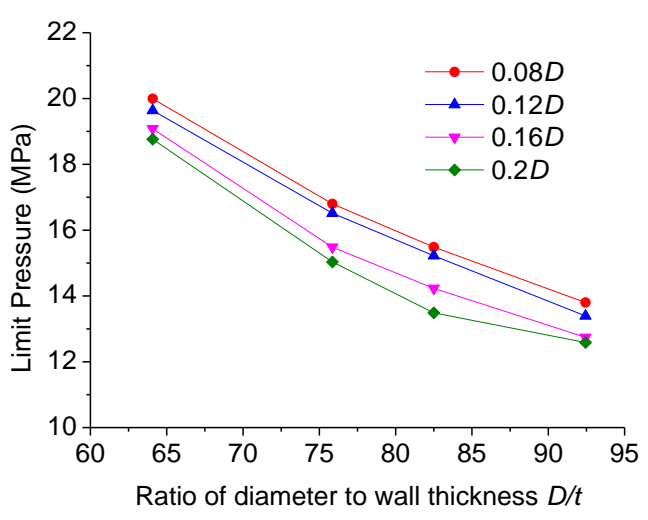

Fig. 12 Effects of Ratio of pipe diameter to wall thickness on pipe limit pressure

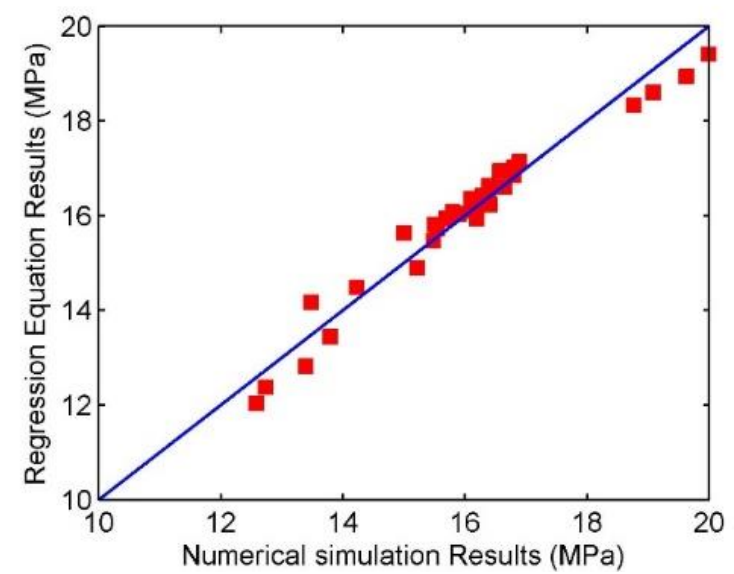

Fig. 13 Comparison of the predicting results with numerical simulation results

\section{Conclusions}

Limit pressure of dented X60 steel pipeline was investigated numerically in this study. A rigorous 3D finite element model was established by software package ABAQUS and validated by previous full scale results. Effects of the dent depth, dent size, initial pressure and ratio of diameter to wall thickness were discussed in detail. Some conclusion can be drawn as below:

1. Although large equivalent stress and plastic strain occurs in the dent area of pipe, numerical results show that, for X60 steel pipe, if dent depth is less than $0.08 \mathrm{D}$, influence of dent on pipe limit pressure is negligible. If dent depth is larger than $0.08 \mathrm{D}$, limit pressure decreases as dent depth increases.

2. With the same dent depth, limit pressure increases with the decrease of indenter diameter, for larger bending strain induced, and limit pressure decreases with the increase of initial internal pressure and ratio of diameter to wall thickness, for larger initial stress induced.

3. A limit pressure prediction equation was proposed by regression analysis. Comparison results show the predicted results are in good agreement with 3D nonlinear finite element results.

\section{Acknowledgements}

The financial support provided by National Key Research and Development Program under Grant No. 2016YFC0802105 is gratefully acknowledged.

\section{References}

1. Liu, X.B.; Zhang, H.; Han, Y.S.; et al. 2016. A semiempirical model for peak strain prediction of buried X80 steel pipelines under compression and bending at strike-slip fault crossings. Journal of Natural Gas Science \& Engineering 32:465-475. https://doi.org/10.1016/j.jngse.2016.04.054.

2. Liu, X.B.; Zhang, H.; Li, M.; et al. 2016. Effects of steel properties on the local buckling response of high strength pipelines subjected to reverse faulting. Journal of Natural Gas Science \& Engineering 33:378-387. https://doi.org/10.1016/j.jngse.2016.05.036.

3. Dawson, S.J.; Russell, A.; Patterson, A. 2006. Emerging Techniques for Enhanced Assessment and Analysis of Dents. Proceedings of 6th International Pipeline Conference, Calgary, Alberta, Canada. https://doi.org/10.1115/IPC2006-10264.

4. Ellinas, C.P.; Walker, A.C. 1983. Damage on Offshore Tubular Bracing Members. Colloquium on Ship Collision with Bridges and Offshore Structures 42(1): 253-261.

5. Wu, Y.; Xiao, J.; Zhang, P. 2016. The analysis of damage degree of oil and gas pipeline with type II plain dent. Engineering Failure Analysis 66: 212-222. https://doi.org/10.1016/j.engfailanal.2016.04.004.

6. Yang, Q.; Shuai, J. 2010. Engineering evaluation method for dented pipeline. Acta Petrolei Sinica 31(4): 649-653. https://doi.org/10.7623/syxb201004025.

7. Jiao, Z.L. 2011. Integrity assessment of pipeline with dents. Journal of Southwest Petroleum University 33(4): 157-164.

https://doi.org/10.3863/j.issn.1674 - 5086.2011.04.030.

8. Allouti, M.; Schmitt, C.; Pluvinage, G.; et al. 2012. Study of the influence of dent depth on the critical pressure of pipeline. Engineering Failure Analysis 21(1): 40-51. https://doi.org/10.1016/j.engfailanal.2011.11.011.

9. Limam, A.; Lee, L.H.; Kyriakides, S. 2012. On the collapse of dented tubes under combined bending and internal pressure. International Journal of Mechanical Sciences 55(1): 1-12. https://doi.org/10.1016/j.ijmecsci.2011.10.005.

10. Zhang, J.; Liang, Z.; Han, C.J. 2015. Numerical simulation of mecanical behavior of buried pipeline impacted by perilous rock. Mechanika 21(4): 264-271. https://doi.org/10.5755/j01.mech.21.3.10134.

11. ABAQUS, 2014. 'User's Manual', Version 6.14. Dassault Systemes. Hebbit, Karlsson and Sorensen Inc.

12. Ma, B.; Shuai, J.; Liu, D.; et al. 2013. Assessment of failure pressure of high strength pipeline with corrosion defects. Engineering Failure Analysis 32: 209-210. https://doi.org/10.1016/j.engfailanal.2013.03.015.

13. American Petroleum Institute. 1999. API 1156 Effects of Smooth and Rock Dents on Liquid Petroleum Pipelines. Washington, DC. 
14. ASME B31.4-2006. Pipeline transportation systems for liquid hydrocarbons and other liquids.

15. ASME B31.8-2003. Gas transmission and distribution piping systems.

Xiaoben Liu, Hong Zhang, Baodong Wang, Mengying Xia, Kai Tang, Kai Wu

\section{NONLINEAR FINITE ELEMENT ANALYSIS OF THE LIMIT STATE AND PRESSURE OF DENTED X60 STEEL PIPELINE}

S u m m a r y

As a main defect in pipeline, dents have brought great challenge to the integrity of oil and gas pipelines. Numerical study was presented in this paper to investigate the stress and strain state of dented X60 pipe. Suitable failure criteria is adopted and validated by full scale experimental results. And the failure process of dented X60 pipe is elucidated in detail. Based on the established model, effects of dent depth, indenter diameter, initial internal pressure, ratio of diameter to ratio thickness on limit pressure of dented pipe was discussed. Finally, a regression based prediction equation for dented X60 pipe was proposed. Results show this equation predicts accurate results with much less effort and time with regard of $3 \mathrm{D}$ finite element models.

Keywords: Numerical modelling, X60 steel pipeline, dent defect, failure pressure, regression equation.

Received December 27, 2016 Accepted December 07, 2017 